Rakenteiden Mekaniikka (Journal of Structural Mechanics)

Vol. 50, No 3, 2017, pp. $304-308$

https://rakenteidenmekaniikka.journal.fi/index

https://doi.org/10.23998/rm.65059

(c) The author(s) 2017.

Open access under CC BY-SA 4.0 license.

\title{
QT steel very high cycle fatigue testing with ultrasonic
}

Jussi Korhonen, Juha Kuoppala ${ }^{1}$, Miikka Väntänen, Joona Vaara, Mikko Turunen, Panu Kämäräinen, Jarkko Laine, Aulis Silvonen and Tero Frondelius

Summary. This article describes the fatigue testing of QT steel in ultrasonic frequencies. Different possibilities, challenges and prejudices are reviewed.

Key words: fatigue testing, very high cycle fatigue, QT-steel

Received 22 June 2017. Accepted 14 August 2017 Published online 21 August 2017

\section{Introduction}

Dynamically loaded components are susceptible to fatigue failures. The concepts of infinite fatigue life and asymptotic S-N curve have been proven false in many occasions [8]. The lack of a fatigue limit in certain materials having a face-centred-cubic (fcc) crystal structure, such as aluminium alloys, is a known phenomenon. However, materials with body-centred-cubic (bcc) crystal structures have been regarded to exhibit an infinite fatigue life below a certain stress amplitude [11]. This is typically considered to be the case with quenched and tempered steels (from now on QT steels) which are widely used in components that have to resist variable loading.

The testing frequencies used in conventional fatigue testing have acted as a limiting factor for fatigue research of materials. Testing beyond $1 \mathrm{e} 7$ or $1 \mathrm{e} 8$ cycles with sufficient sample sizes would simply take an unreasonable amount of time. However, there is a considerable demand for fatigue testing with the VHCF (i.e. Very High Cycle Fatigue) regime for materials used in components that experience over 1e8 load cycles during their lifetimes $[4,12,7]$. For example, the fatigue strength of a high strength steel can change as much as 50-200 MPa from 1e6 cycles to 1e9 cycles [8].

A solution to the frequency problem is accelerated testing using piezoelectric excitation in ultrasonic frequencies. Global Boiler Works Oy conducts ultrasonic fatigue experiments with equipment developed by the Institute of Physics and Materials Science at University of Natural Resources and Life Sciences, Vienna (Physics BOKU Vienna). This equipment enables intermittent testing, which is essential to combat the heating of specimens vibrating with a resonance close to $20 \mathrm{kHz}$. An example of a test setup with this equipment is

${ }^{1}$ Corresponding author. juha.kuoppala@gbw.fi 
shown in figure 1. In the example, a mean load is applied to the specimen with a load frame and an elevated temperature is used in the heating chamber.

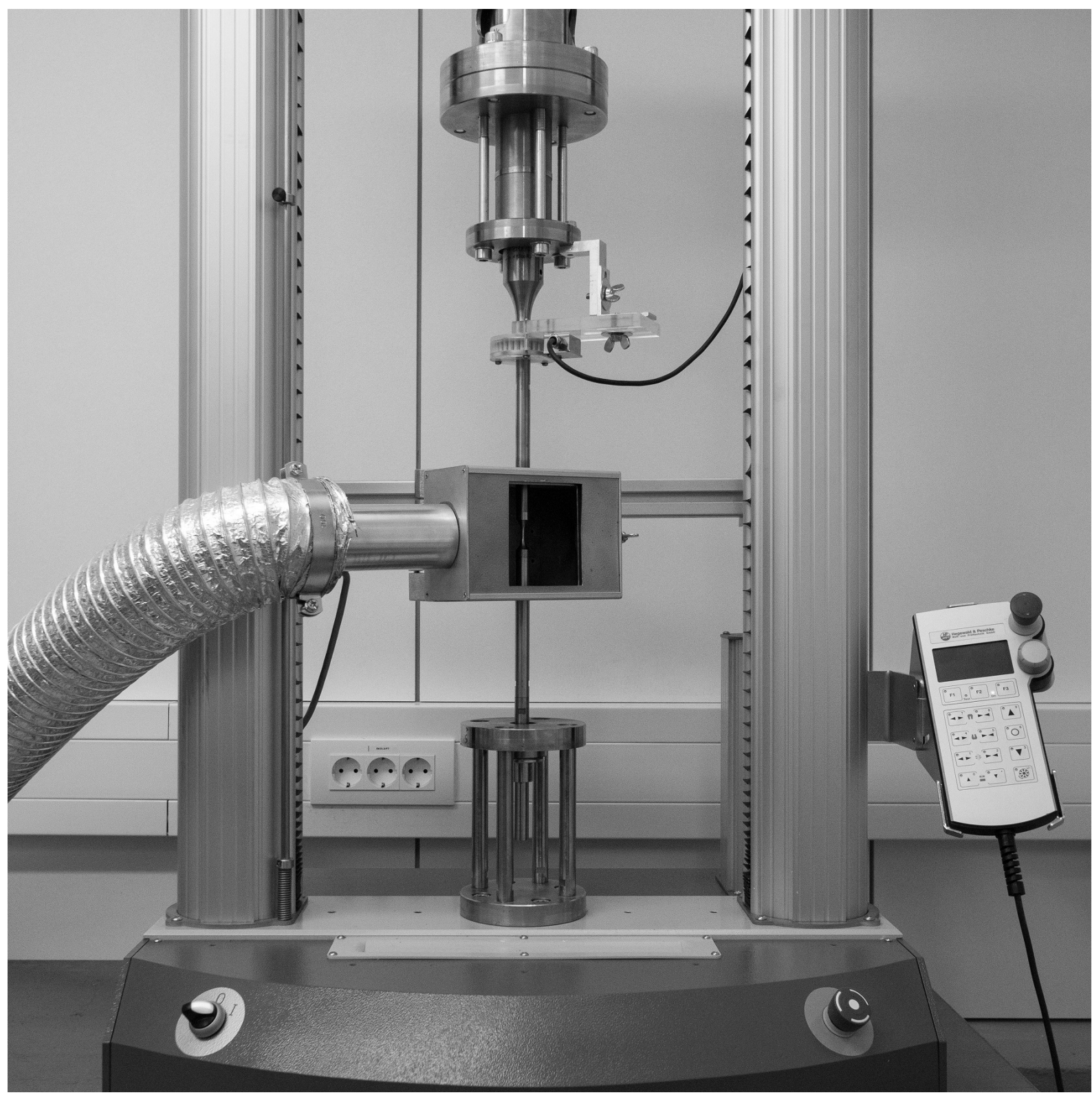

Figure 1. An example of a test setup with applied mean load and elevated temperature

\section{Ultrasonic fatigue testing of QT steels}

QT steels are frequently used in dynamically loaded machine components. In this paper, 34CrNiMo6 is used as an example. It is regarded as a low-alloy high-strength steel in fatigue literature [9]. The material in question is used in components, for example crankshafts, that can experience over 1 e9 cycles during their service life. Thus conventional fatigue testing is not efficient in assessing the fatigue properties of this material. An example of the results from ultrasonic fatigue tests done by Global Boiler Works Oy is presented in figure 2. It can be noted that the runout limit of $1 \mathrm{e} 8$ chosen for this test 
series was insufficient since there are failures beyond that number of cycles also.

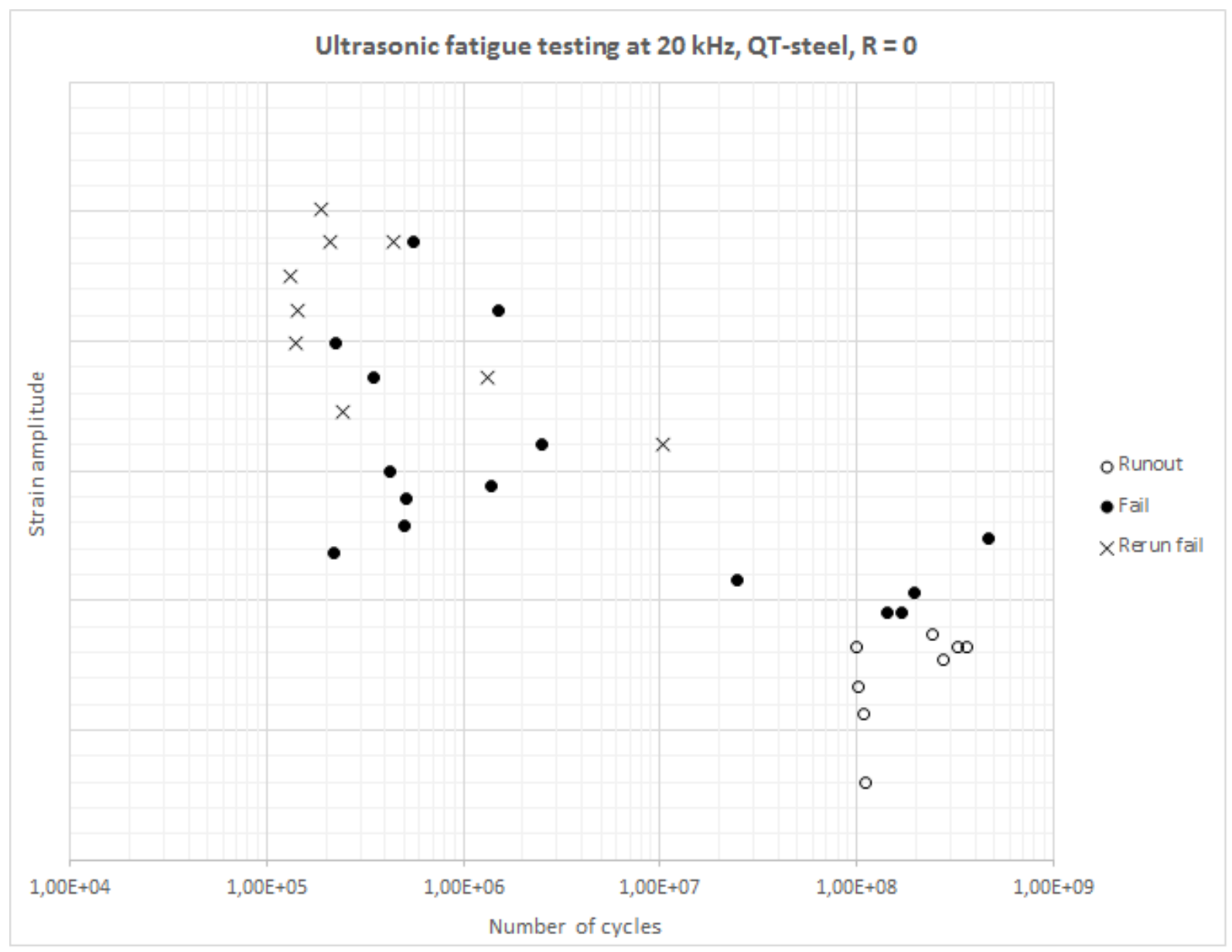

Figure 2. An example of ultrasonic fatigue test results of QT-steel

When ultrasonic fatigue testing is employed, the correspondence of the results acquired via ultrasonic testing and conventional testing must be considered. A much debated topic is the effect of the testing frequency on the measured fatigue life. This depends on the material that is tested, generally the influence of frequency is stronger in bcc metals than in fcc metals [9]. In general, if the effect is noticeable, the results obtained with ultrasonic testing frequencies show better fatigue properties. Mayer [9] has gathered, that for high strength steels, the frequency effect is generally negligible. Also, according to Ebara [3], the possible frequency effects are mostly observed with high testing amplitudes and not near the amplitude levels of the supposed fatigue limit. This finding is backed up by Mayer et al's [6] study on near-threshold fatigue crack growth in aluminium for both 20 $\mathrm{Hz}$ and $20 \mathrm{kHz}$ testing frequencies. They concluded that below the $10^{-9} \mathrm{~m} /$ cycle, i.e. near the threshold value, the testing frequency did not have any effect.

Another thing to consider when comparing ultrasonic fatigue test results to those obtained by conventional low frequency testing is the possible size effect. Furya [5] concluded that, if a high strength steel specimen used for ultrasonic testing has different risk volume than the specimen geometry used for conventional fatigue testing, the results from ultrasonic testing will indicate a higher fatigue strength than those from conventional testing. A proposed cause of this is the higher possibility of significant defects in a larger testing 
volume which leads to a lower fatigue strength of the specimen with a larger stressed volume. With equal highly stressed volumes, there is good agreement between conventional and ultrasonic fatigue test results. [5]

Regarding the expected results, Bathias et al. [2] identified three different types of fatigue crack initiation. Their findings are based on cylindrical samples with polished surfaces, i.e. the type of specimens generally used in ultrasonic fatigue testing. Bathias et al. [2] state that, in the low cycle regime (1e4 cycles), crack initiations are typically multiple and located on the surface. In a megacycle regime (1e6 cycles), crack initiation occurs on the surface but from a single point. In the gigacycle regime (1e9 cycles), crack initiation occurs in the internal zone. Bathias et al. [2] note that there are exceptions to this phenomenon and it is not universal to all materials. Marines et al. [8] go further categorizing the resulting failure populations. When VHCF results are plotted on an S-N curve, a step may be observed as well as some significant scatter around 1e6 cycles. According to Marines et al. [8] this is due to the competition of the surface crack initiation and internal initiation. They were able to separate two different $\mathrm{S}-\mathrm{N}$ curves from the results, one for each crack initiation mode.

The ultrasonic fatigue testing method offers great versatility. Tests can be conducted in elevated or cryogenic temperatures, high gas pressures, a vacuum and with different mean loads. Fretting corrosion, torsion and three-point bending fatigue experiments are also possible. [1]

These experiments can also be run on variable amplitudes, which makes it possible to create arrest marks that make it possible to calculate the crack growth rate from the fracture surface. [10]

\section{Conclusions}

According to literature sources and authors' experience, ultrasonic fatigue testing is a suitable method for studying the fatigue properties of QT steel. The results obtained via ultrasonic fatigue testing should coincide well with conventional testing results if the highly stressed volume in the testing specimens is equal. The ultrasonic method is preferable because testing the VHCF regime with conventional methods is impractical due to the amount of time required. For typical utilization of QT steels, the knowledge of fatigue behavior in the VHCF regime is essential. Due to the versatility of the ultrasonic method, it is also possible to run tests, for example, in specific environments or load ratios.

\section{References}

[1] C. Bathias. Piezoelectric fatigue testing machines and devices. International Journal of Fatigue, 28(11):1438-1445, 2006. ISSN 0142-1123. URL https://doi.org/10.1016/j. ijfatigue.2005.09.020.

[2] C. Bathias, L. Drouillac, and P. Le François. How and why the fatigue s-n curve does not approach a horizontal asymptote. International Journal of Fatigue, 23(S1):143-151, 2001. ISSN 0142-1123. URL https://doi.org/10.1016/S0142-1123(01)00123-2.

[3] R. Ebara. The present situation and future problems in ultrasonic fatigue testing - mainly reviewed on environmental effects and materials screening. International Journal of Fatigue, 28(11):1465-1470, 2006. ISSN 0142-1123. URL https://doi.org/10.1016/j.ijfatigue. 2005.04 .019 . 
[4] Tero Frondelius, Pasi Halla-aho, and Antti Mäntylä. Crankshaft development with virtual engine modelling. In CIMAC Congress Helsinki, 2016.

[5] Y. Furuya. Specimen size effects on gigacycle fatigue properties of high-strength steel under ultrasonic fatigue testing. Scripta Materialia, 58(11):1014-1017, 2008. ISSN 1359-6462. URL https://doi.org/10.1016/j.scriptamat.2008.01.039.

[6] B Holper, H Mayer, AK Vasudevan, and SE Stanzl-Tschegg. Near threshold fatigue crack growth at positive load ratio in aluminium alloys at low and ultrasonic frequency: influences of strain rate, slip behaviour and air humidity. International journal of fatigue, 26(1):27-38, 2004. URL https://doi.org/10.1016/S0142-1123(03)00092-6.

[7] Anton Leppänen, Asko Kumpula, Joona Vaara, Massimo Cattarinussi, Juho Könnö, and Tero Frondelius. Thermomechanical fatigue analysis of cylinder head. Rakenteiden Mekaniikka, 50(3):182-185, 2017. URL https://doi.org/10.23998/rm.64743.

[8] I. Marines, X. Bin, and C. Bathias. An understanding of very high cycle fatigue of metals. International Journal of Fatigue, 25(9-11):1101-1107, 2003. ISSN 0142-1123. URL https: //doi.org/10.1016/S0142-1123(03)00147-6.

[9] H. Mayer. Recent developments in ultrasonic fatigue. Fatigue \& Fracture of Engineering Materials 85 Structures, 39(1):3-29, 2015. ISSN 1574-6968. URL https://doi.org/10. $1111 /$ ffe. 12365.

[10] M. Sander, T. Müller, and J. Lebahn. Influence of mean stress and variable amplitude loading on the fatigue behaviour of a high-strength steel in vhcf regime. International Journal of Fatigue, 62(1):10-20, 2013. ISSN 0142-1123. URL https://doi.org/10.1016/ j.ijfatigue.2013.04.015.

[11] C. M. Sonsino. Course of sn-curves especially in the high-cycle fatigue regime with regard to component design and safety. International Journal of Fatigue, 29(12):2246-2258, 2006. ISSN 0142-1123. URL https://doi.org/10.1016/j.ijfatigue.2006.11.015.

[12] Ilkka Väisänen, Antti Mäntylä, Antti Korpela, Teemu Kuivaniemi, and Tero Frondelius. Medium speed engine crankshaft analysis. Rakenteiden Mekaniikka, 50(3):341-344, 2017. URL https://doi.org/10.23998/rm.64916.

Jussi Korhonen, Juha Kuoppala, Miikka Väntänen

Global Boiler Works Oy

Lumijoentie 8

90400 Oulu

jussi.korhonen@gbw.fi, juha.kuoppala@gbw.fi, miikka.vantanen@gbw.fi

Joona Vaara, Mikko Turunen, Panu Kämäräinen, Jarkko Laine, Aulis Silvonen, Tero Frondelius Wärtsilä

Järvikatu 2-4

65100 Vaasa

joona.vaara@wartsila.com, mikko.turunen@wartsila.com, panu.kamarainen@wartsila.com, jarkko.laine@wartsila.com, aulis.silvonen@wartsila.com, tero.frondelius@wartsila.com 